\title{
RECOMENDAÇÕES EM AUDITORIA OPERACIONAL: UMA PROSPECÇÃO DE FRAGILIDADES, COM BASE NA INTELIGÊNCIA COMPETITIVA
}

\author{
RECOMMENDATIONS IN OPERATIONAL AUDITORSHIP: \\ A PROSPECTION OF FRAGILITIES, ON THE BASIS OF \\ COMPETITIVE INTELLIGENCE
}

\author{
José Francisco Ribeiro Filho ${ }^{1}$, Jorge Expedito de Gusmão \\ Lopes $^{2}$, Marcleide Maria Macedo Pederneiras ${ }^{3}$, \\ Alan José de Moura Silva ${ }^{4}$ e Caio Eduardo Silva Mulatinho ${ }^{5}$
}

\begin{abstract}
Resumo
A sociedade brasileira vem se apercebendo da importância de exigir a utilização responsável dos recursos públicos, postos à disposição de seus representantes eleitos, revertendo-os em benefícios que atendam às necessidades dos cidadãos. Os órgãos de controle externo começam a se preocupar com o atingimento de metas e melhoria de padrões de desempenho das políticas públicas e passam a realizar auditorias de natureza operacional, que buscam avaliar a gestão do ponto de vista da economicidade, eficiência e eficácia, bem como da efetividade das despesas governamentais. Esta pesquisa verificou se era possível identificar fragilidades que comprometessem a eficácia das recomendações emitidas pelas auditorias operacionais realizadas pelo Tribunal de Contas do Estado de PE, a partir do conceito de inteligência competitiva e com vistas a subsidiar uma atuação preventiva e/ou contingencial. Utilizou-se do método dedutivo com pesquisa bibliográfica e documental, com a análise de todas as recomendações das auditorias operacionais realizadas e julgadas pelo TCE/PE de 2003-2007. Concluiu-se, com base na inteligência competitiva, que há fragilidades que podem comprometer a eficácia da implementação das recomendações emitidas pela auditoria operacional, que uma vez identificadas permitirão o estabelecimento de uma estratégia preventiva e uma estratégia contingencial, para fazer face aos fatores de risco, caso se concretizem. Contingencial.

Palavras-chave: Auditoria; Controle Externo; Inteligência Competitiva; Economicidade; Estratégia

\footnotetext{
1 Doutor. Professor de Graduação e Pós-Graduação lato e stricto sensu da Universidade Federal de Pernambuco (UFPE). E-mail: francisco.ribeiro@ufpe.br

2 PhD. Professor de Graduação e Pós-Graduação lato e stricto sensu da UFPE. E-mail: jlopes@ufpe.br

3 Mestre. Professora de Graduação e Pós-Graduação lato sensu da Universidade Federal da Paraíba (UFPB).

E-mail: marcleide@gmail.com

4 Mestrando. Professor de Graduação. E-mail: alansilva@tce.pe.gov.br

5 Mestre. Professor de Graduação e Pós Graduação lato sensu. E-mail: caiomulatinho@yahoo.com.br
} 


\begin{abstract}
The Brazilian company has been aware of the importance of requiring the responsible use of public resources, made available to their elected representatives, reverting them into benefits that meet the needs of citizens. The bodies of external control are beginning to worry about achievement of targets and improvement of the performance of public policy and start to perform audits of an operational nature, seeking to evaluate the management in terms of economy, efficiency and effectiveness, and the effectiveness of government expenditure. This research examined whether it was possible to identify weaknesses that jeopardise the effectiveness of the recommendations issued by operational audits conducted by the Court of the State of $P E$, from the concept of competitive intelligence and in order to subsidize a preventive action and / or contingencial. It was used the deductive method with literature search and documentary, with the analysis of all the recommendations of audits conducted operational and judged by the ECA / PE 2003-2007. It was concluded on the basis of competitive intelligence, that there are weaknesses that could compromise the effectiveness of implementing the recommendations issued by the operational audit, which once identified will allow the establishment of a preventive strategy, and contingencial a strategy to tackle the risk factors If materialise.
\end{abstract}

Keywords: Audit; External Control; Competitive Intelligence; Economy; Strategy Contingencial.

\title{
1 Introdução
}

A Reforma do Estado Brasileiro promoveu mudanças profundas na Administração Pública, que passou a se voltar para resultados, ou seja, passou a adotar enfoque gerencial em detrimento do burocrático.

Essas mudanças vêm afetando a sociedade brasileira, que está se apercebendo, gradativamente, da importância de exigir a utilização responsável dos recursos públicos, postos à disposição de seus representantes eleitos, revertendo-os em benefícios que atendam às necessidades dos cidadãos. A sociedade civil tem se robustecido através dos movimentos sociais, forjando um novo sentido de cidadania, comprometido com valores de equidade, participação, transparência e ética na administração pública. (CARVALHO, 2005).

Os órgãos de controle externo do mundo têm buscado o aprimoramento de suas ações, voltando-se também para o acompanhamento do desempenho de entidades e políticas públicas. O que se observa de um modo geral é que há uma nítida preocupação com o aperfeiçoamento dos mecanismos de avaliação dos resultados dos programas de governo, com ênfase na efetividade e na análise do processo de tomada de decisões. (RIBEIRO, 2004, p. 90).

Nesse contexto, no Brasil e em particular no caso do Tribunal de Contas da União, passou-se a realizar auditorias operacionais a partir de 1998 em conformidade com a Constituição Federal (BRASIL, 2007, p. 98), que prevê:

Art. 70. A fiscalização contábil, financeira, orçamentária, operacional e patrimonial da União e das entidades da administração direta e indireta, quanto à legalidade, legitimidade, economicidade, aplicação das subvenções e renúncia de receitas, será exercida pelo Congresso Nacional, mediante controle externo e pelo sistema de controle interno de cada Poder.[...]

Art. 71. O controle externo, a cargo do Congresso Nacional, será exercido com o auxílio do Tribunal de Contas da União, ao qual compete [...].

Segundo a International Organization of Supreme Audit Institutions, a auditoria operacional ou de gestão preocupa-se em determinar se as atividades foram executadas com economia, conforme princípios, práticas e políticas administrativas corretas; se os recursos dis-

Rev. Adm. UFSM, Santa Maria, v. 3, n. 2, p. 191-204, mai./ago. 2010 
poníveis são utilizados com eficiência, examinando os sistemas de informação, os procedimentos de mensuração e controle do desempenho, as providências adotadas para sanar deficiências detectadas e a eficácia do desempenho em relação ao alcance de seus objetivos, bem como a relação entre os resultados alcançados e os pretendidos. (INTOSAI, 2004).

Pode-se, então, afirmar que o Tribunal de Contas da União, sintonizado com a tendência mundial e em conformidade com o novo paradigma de gestão implantado a partir da Reforma do Estado, começa a se preocupar com o "atingimento de metas, com a melhoria dos padrões do desempenho administrativo e os resultados esperados das ações e das políticas públicas implementadas". (CARVALHO, 2005, p. 129).

O Tribunal de Contas do Estado de Pernambuco realizou os primeiros trabalhos de auditoria de natureza operacional em 2003 e, a partir de 2004, passou a realizá-las com base na metodologia utilizada pelo TCU, através de grupo de trabalho especialmente criado para implementação e desenvolvimento desse tipo de auditoria no âmbito do controle externo de Pernambuco, focando seus trabalhos na avaliação de programas governamentais, com vistas a contribuir com a redução da pobreza e das desigualdades sociais, tendo como consequência uma gestão eficaz e com responsabilidade social no setor público.

Assim, observa-se, no âmbito estadual, o reconhecimento gradual da importância e da necessidade de se avaliar não apenas os aspectos da legalidade, mas também os de economicidade, eficiência e eficácia, bem como os de efetividade das despesas governamentais.

Entretanto, avaliar tais aspectos não garante o aperfeiçoamento do desempenho dos órgãos ou programas governamentais auditados. É necessário que o Tribunal de Contas acompanhe a implementação das recomendações exaradas. "Um processo de acompanhamento facilitará a execução eficaz das recomendações dos relatórios". (INTOSAI, 2004, p. 88).

Em outras palavras, é necessário que as auditorias operacionais sejam eficazes quanto à implementação das recomendações que emitir. Os monitoramentos ganham, assim, importância central e exigem cuidados das equipes envolvidas com as auditorias, a fim de verificar se os gestores estão considerando em seus planejamentos as recomendações emitidas e de fato as estão implementando; afinal de contas; os trabalhos do controle externo não podem ser vistos como os de uma consultoria, em que o avaliado pode ou não acatar suas conclusões.

Ao final da auditoria, o gestor deve elaborar um Plano de Ação, se possível com a participação de membros da equipe de auditoria, que sirva de base para realização dos monitoramentos.

Dessa forma, são realizados de dois a três monitoramentos para cada auditoria. Este processo deve encerrar-se em, aproximadamente, 24 meses após a publicação da Decisão emitida pelo Tribunal, quando será elaborado um relatório final de impacto da auditoria.

Entretanto, fica a dúvida se as recomendações elaboradas estão sujeitas a fragilidades que comprometam a eficácia de sua implementação e se essas fragilidades podem ser identificadas a priori, permitindo uma atuação preventiva e/ou contingencial.

Assim, foi trabalhada a seguinte questão: será possível identificar fragilidades que possam comprometer a eficácia das recomendações emitidas pelas auditorias operacionais realizadas pelo Tribunal de Contas do Estado de Pernambuco, com base na inteligência competitiva?

O objetivo deste trabalho foi verificar se era possível identificar fragilidades que comprometessem a eficácia das recomendações supracitadas, com base na inteligência competitiva e com vistas a subsidiar uma atuação preventiva e/ou contingencial. 


\section{Referencial teórico}

\subsection{Conceito de eficácia}

A auditoria operacional trabalha na expectativa de avaliar programas e órgãos governamentais na perspectiva da economicidade, eficiência, eficácia e da efetividade. Para o presente trabalho, é preciso entender bem a diferença entre essas dimensões, a fim de que se possam obter resultados coerentes, especialmente no que tange ao entendimento do que seja eficácia.

Existem inúmeras conceituações a respeito dessas dimensões do desempenho e, dessa forma, serão apresentadas aquelas adotadas pelos órgãos de controle externo no Brasil, especialmente pelo Tribunal de Contas da União.

Supondo, para melhor compreensão dos conceitos, que em determinada região haja alta incidência de mortalidade infantil e o gestor resolve elaborar um programa de vacinação específico para aquela região. Após fazer seu planejamento, inicia-se a implementação do programa, com a realização de uma licitação para adquirir 14.000 vacinas, que serão aplicadas, obviamente, em 14.000 crianças. A empresa que ofereceu o menor valor vence o certame, e as vacinas são adquiridas. Considerando que o preço é coerente com o ofertado no mercado, pode-se afirmar que a gestão atendeu ao princípio da economicidade, que representa a:

\footnotetext{
Minimização dos custos dos recursos utilizados na consecução de uma atividade, sem comprometimento dos padrões de qualidade. Refere-se à capacidade de uma instituição de gerir adequadamente os recursos financeiros colocados a sua disposição. (BRASIL, 2000, p.15).
}

A meta é vacinar essas crianças no prazo de até três meses, gastando uma quantia de \$ 100.000 unidades monetárias. Porém, se a equipe conseguir cumprir sua meta antes dos três meses ou, ainda, se conseguir realizar o trabalho sem gastar os $\$ 100.000$, pode-se afirmar que a gestão atendeu ao princípio da eficiência, que é a:

\footnotetext{
Relação entre os produtos (bens e serviços) gerados por uma atividade e os custos dos insumos empregados para tal em um determinado período de tempo. Se a quantidade de produto está predeterminada, procura-se minimizar o custo total; se o gasto total está previamente fixado, procura-se otimizar a combinação de insumos para maximizar o produto; em ambos os casos a qualidade deve ser mantida. Essa dimensão, portanto, mede o esforço do processo de transformação de insumos em produtos. (BRASIL, 2000, p.15).
}

Por outro lado, pode-se afirmar que, se a gestão conseguiu vacinar todas as supracitadas crianças, independentemente dos custos e dos prazos envolvidos, ela foi eficaz, que é o grau de alcance das metas programadas em um determinado período de tempo, independentemente dos custos implicados. (BRASIL, 2000, p.15).

É bem sutil a diferença entre eficiência e eficácia, porém, uma vez identificada, não fica margem para dúvidas, pois a eficácia é fazer o que tem que ser feito, enquanto a eficiência é fazer algo da melhor forma possível.

E, por fim, surge o conceito de efetividade, mais abrangente e obviamente mais importante, pois ele determina se os objetivos alcançados foram suficientes para solucionar $\mathrm{o}$ problema que deu origem, no presente caso, à atuação governamental. Se a mortalidade infan- 
til após a realização do programa de vacinação reduzir, pode-se afirmar que foi atendido o princípio da efetividade, que implica a "relação entre os resultados alcançados e os objetivos que motivaram a atuação institucional, entre o impacto previsto e o impacto real de uma atividade". (BRASIL, 2000, p.15).

Porém, cabe observar que, se o problema e suas causas foram adequadamente identificados - no exemplo dado pressupõe-se que a causa do alto índice de mortalidade infantil esteja associado à baixa imunização da população com relação a determinadas doenças -, a efetividade só será alcançada se houver a eficácia, considerando que o problema poderia ser resolvido mesmo que gastando além do necessário, ou seja, sem eficiência e/ou economicidade.

Diante do exposto, pode-se inferir que, se há a expectativa de que as recomendações emitidas durante as auditorias operacionais em programas governamentais contribuam para o aperfeiçoamento da gestão, a eficácia na implementação das referidas recomendações tornase de fundamental importância.

\subsection{Inteligência competitiva e setor governamental}

O avanço da tecnologia e a redução das fronteiras comerciais promoveram o aumento do volume e da velocidade do fluxo de informações e, consequentemente, as mudanças no ambiente socioeconômico passaram a ocorrer de forma vertiginosa.

Para continuar no jogo, é necessário capacidade de reação, bem como tempo de reação das organizações, para que as elas possam se tornar claramente orientadas para o mercado e para as oportunidades que estão surgindo. (POZZEBON et al., 1997).

Com as crescentes e velozes mudanças na era do conhecimento, atualmente vivenciada, as entidades se veem diante do desafio de obter e gerar informações de forma tempestiva, com o fim de não serem surpreendidas por contingências. Segundo Valentim (2002), a sociedade da informação traz paradigmas da economia, como produtividade e qualidade e cria novos caminhos para o desenvolvimento. Dessa forma,exige uma nova postura diante das mudanças sociais, pois gerar, obter e aplicar conhecimento passa a ser item básico para enfrentar essas mudanças.

Nesse sentido surge a discussão acerca da inteligência competitiva:

A inteligência competitiva é o processo que investiga o ambiente onde a empresa está inserida, com o propósito de descobrir oportunidades e reduzir os riscos, bem como diagnostica o ambiente interno organizacional, visando o estabelecimento de estratégias de ação a curto, médio e longo prazo. (VALENTIM et al., 2003, p. 2).

Como se pode observar, a inteligência competitiva desperta no ambiente organizacional a preocupação em estar devidamente preparado para as oportunidades e riscos, através de estratégias que levem em consideração as possíveis mudanças futuras.

O setor governamental não escapa dessa perspectiva, pois suas organizações também sofrem diversas influências que podem representar riscos ou oportunidades à sua atuação, sendo oportuna a utilização em suas diversas ações dos cuidados oriundos de uma prática de inteligência competitiva. 


\subsection{Informação e vigília}

É preciso considerar que, para se adotar a inteligência competitiva, deve-se estar atento ao processo de obtenção da informação, pois, no dizer de Palop e Vicente Gomila (1999, p. 22, apud VALENTIM, 2002),

o monitoramento é um esforço sistematizado e organizado pela empresa para observação, captação, análise, difusão precisa e recuperação de informações sobre o entorno econômico, tecnológico, social ou comercial, indicando ameaças ou oportunidades para a mesma.

Para Valentim (2002), a inteligência competitiva necessita do mapeamento e da prospecção de dados, informações e conhecimento produzidos interna e externamente à organização.

Dessa forma, um dos aspectos mais importantes a ser considerado quando se trabalha a partir do conceito de inteligência competitiva, é denominado de vigília e está previsto na literatura francesa, mas também é chamado em outros países de monitoramento. Adotou-se o termo vigília, no presente trabalho, para evitar confusões com o termo monitoramento, também utilizado nas auditorias operacionais, como já explicado.

Segundo Valentim (2002), da análise da literatura francesa surgem três tipos de vigília, a saber: a vigília científica e técnica muito voltada para a pesquisa e desenvolvimento; a vigília tecnológica focada no produto e na tecnologia utilizada para desenvolvê-lo e a vigília concorrencial e comercial voltada para o exame do ambiente, para a competição no mercado, objetivando observar o impacto da venda do produto nesse mercado. Afirma, ainda, que as três vigílias são tratadas como campos distintos da área de inteligência.

O presente trabalho considerou a vigília concorrencial e comercial como objeto de estudo, adequando-a à realidade da auditoria governamental.

No setor governamental, notadamente no setor público, não existe a concorrência nos moldes do setor privado e na auditoria operacional o principal produto a ser ofertado à sociedade são as recomendações oriundas dos trabalhos auditoriais.

Entretanto, por analogia, pode-se considerar que: toda vez que a equipe de auditoria observar o impacto das recomendações estará realizando uma vigília concorrencial. Quando estiver focada nos impactos das recomendações na sociedade de um modo geral, estará observando a dimensão da efetividade e quando estiver focada nos impactos das recomendações, quanto à sua implementação pela gestão dos programas governamentais avaliados, estará observando a dimensão da eficácia.

Diante do exposto, pode-se afirmar que a prospecção de fragilidades que podem afetar a eficácia das recomendações das auditorias operacionais realizadas pelas Cortes de Contas representa trabalho de vigília concorrencial e comercial adaptada à realidade do setor governamental com base no conceito de inteligência competitiva.

\subsection{Plano de contingências}

A identificação de fragilidades nas recomendações emitidas torna-se, então, relevante para que aos primeiros sinais de que contingências associadas a elas irão ocorrer, haja condições para adoção de medidas emergenciais que garantam a eficácia da implementação esperada. 
Para tanto, é necessário o processo contínuo de vigília, mas também a elaboração de Plano de Contingências, que contenha ações específicas para cada tipo de contingência.

Um plano de contingência eficaz, com modos de resposta previamente estudados e praticados facilita a atuação organizada no caso de uma situação de emergência real. (SOUZA FILHO, 2006).

Dessa forma, quando a situação indesejada vier a ocorrer, a equipe responsável pela auditoria operacional saberá o que fazer e terá condições de dar uma resposta tempestiva, evitando que a implementação da recomendação ocorra de forma inadequada, perdendo sua eficácia.

Essa forma de atuação é bastante razoável para qualquer situação que envolva riscos e é extremamente relevante quando o assunto envolve a vida das pessoas.

\footnotetext{
frente à iminência da eclosão de uma pandemia por influenza, faz-se necessário padronizar e intensificar as ações de vigilância epidemiológica de síndrome gripal a fim de tornar o sistema de vigilância o mais oportuno possível. Os dados coletados devem caracterizar a população exposta e identificar as cepas em circulação, especialmente a pandêmica. Além disso, esses dados são importantes para subsidiar a tomada de decisões referentes a tratamento, medicamentos, vacinas, equipamentos de proteção individual e contingente de trabalhadores de saúde, dentre outras estratégias para o enfrentamento da possível pandemia. (SANTA CATARINA, 2006).
}

Nesse sentido, é importante salientar que existem programas governamentais na área de saúde e vigilância sanitária que implicam cuidados com a implementação das recomendações da auditoria operacional, sob pena de colocar em risco a saúde e a vida dos cidadãos.

Por outro lado, saber o que fazer diante de situações emergenciais é fundamental para a sobrevivência de qualquer atividade, conforme observado em pesquisas internacionais:

\footnotetext{
Nos Estados Unidos, estatísticas do U.S. Bureau of Labor estimam que, das empresas que venham a experimentar alguma situação de desastre sem ter um plano de contingência e recuperação, cerca de 43\% nem sequer reabrirão seus negócios após o desastre, $80 \%$ sobreviverão até o primeiro ano seguinte e 93\% encerrarão suas atividades, no máximo, cinco anos depois. A IBM divulgou uma pesquisa na qual afirma que apenas $8 \%$ dos negócios de Internet estão preparados para uma situação de contingência. (SANTOS AMARO, 2005).
}

Assim, é necessário adotar uma política organizacional de segurança, em que estejam definidos os procedimentos de segurança relativos às contingências. Essa prática deve ser utilizada inclusive em pequenas empresas, obviamente que com um grau de complexidade menor, porém com condições de garantir a segurança da organização em situações de risco.

Ainda segundo Santos Amaro (2005), o planejamento das contingências deve obedecer a um ciclo com etapas bem definidas, conforme ilustrado na figura 1 . 


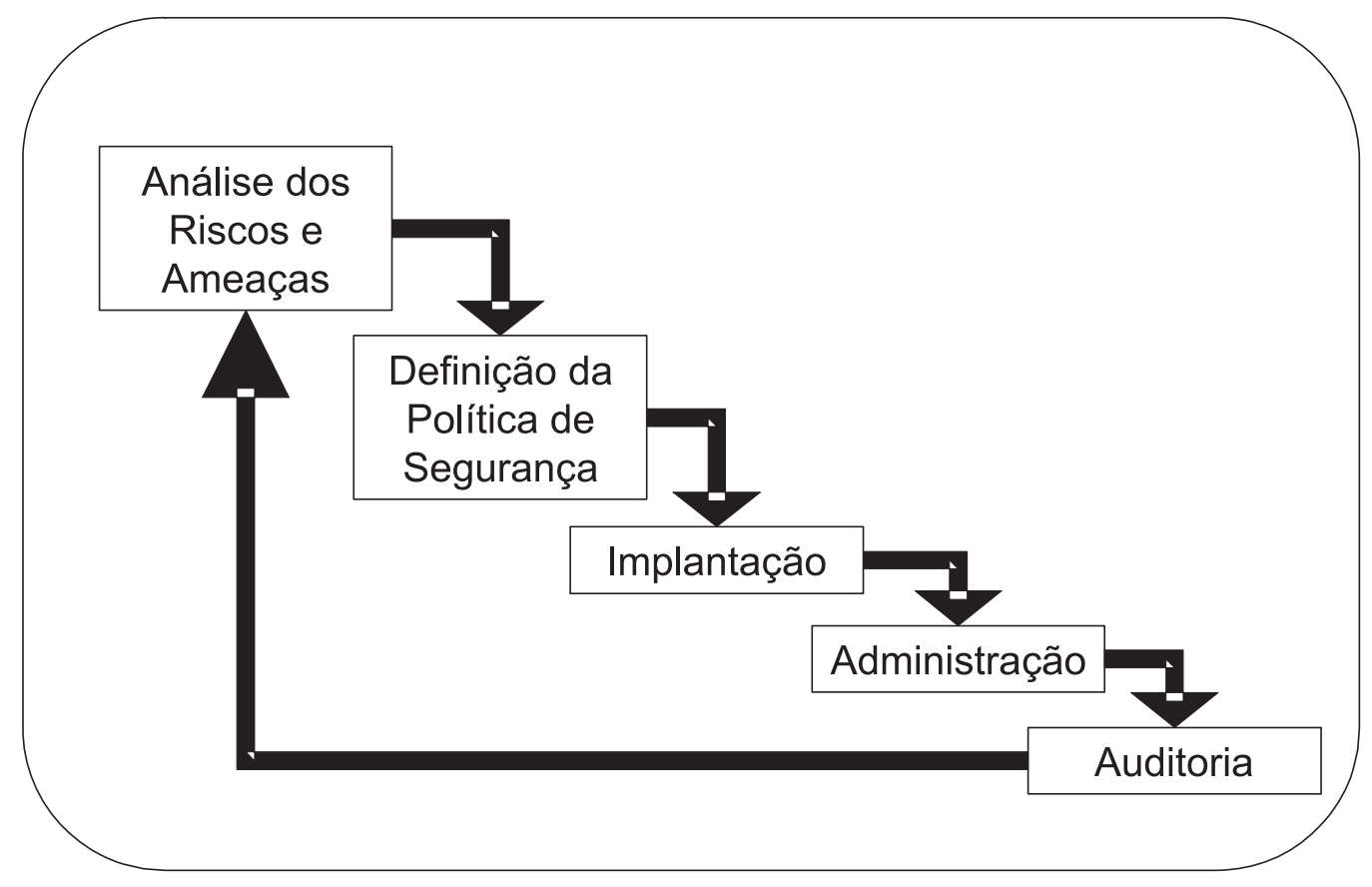

Figura 1 - Etapas do ciclo de segurança

Fonte: Baseado em Santos Amaro (2005).

Diante do exposto e em consonância com os pressupostos desta pesquisa, pode-se afirmar que o processo de vigília - no presente caso, a vigília concorrencial - deve redundar em política de segurança, a partir da prospecção das fragilidades das recomendações e riscos e ameaças a elas associados, que, em sua especificidade, deverá caracterizar-se como um Plano de Contingências, o qual necessitará ser implantado e acompanhado, a fim de retroalimentar o processo de vigília, aperfeiçoando permanentemente a atuação da organização frente às situações emergenciais.

Mas, como se pode observar, tudo começa com a identificação dos riscos e ameaças e, por conta disso, realizou-se uma análise das recomendações emitidas, descrita no próximo item, com o fim de identificar suas fragilidades.

\section{Procedimento metodológico}

Para o desenvolvimento desta pesquisa, utilizou-se do método dedutivo, com a realização de pesquisa bibliográfica e documental, com a análise de todas as recomendações das auditorias operacionais realizadas e julgadas pelo TCE/PE de 2003 até 2007, totalizando 231 recomendações, que foram analisadas uma a uma, na expectativa de observar fragilidades que pudessem comprometer sua eficácia.

Este trabalho não teve a pretensão de esgotar a análise das citadas fragilidades, principalmente porque oferece como limitação um grau de subjetividade, que deve ser levado em consideração. Entretanto, pretendeu-se contribuir para a discussão sobre o assunto e para o aperfeiçoamento desse tipo de auditoria, ainda muito recente no Brasil, no âmbito dos órgãos de controle externo. 


\section{Análise das recomendações e resultados}

Antes de expor os resultados da análise realizada, cabe entender como as recomendações são avaliadas na fase de monitoramento, ou seja, como são classificadas de acordo com o estágio de implementação.

Segundo o último relatório de monitoramento disponível no site do Tribunal de Contas do Estado de Pernambuco, as recomendações são classificadas da seguinte forma:

- Recomendações não mais aplicáveis;

- Recomendações não implementadas;

- Recomendações em fase inicial de implementação;

- Recomendações em fase final de implementação, e

- Recomendações implementadas.

Com base nessas informações, iniciou-se a análise das recomendações das auditorias operacionais, destacando que esse tipo de auditoria é uma atividade realizada em parceria com o gestor - não confundir com consultoria, pois o gestor é obrigado a implementar as recomendações - o qual toma conhecimento de todos os passos e achados da auditoria realizada e que ainda participa em diversas oportunidades de discussões sobre as recomendações que serão exaradas pela equipe de auditoria. Isto porque os gestores são os principais especialistas das áreas em que os programas atuam e, portanto, devem ser permanentemente ouvidos, considerando que a auditoria é propositiva e tem a expectativa de agregar valor ao trabalho realizado.

Assim, espera-se que o gestor tenha o maior interesse em compreender o que deve ser feito para implementar as recomendações e aperfeiçoar de modo geral sua gestão no programa. Mas nem sempre isso ocorre, quer porque o gestor não é comprometido, quer porque outras forças impedem que ele realize as ações de implementação ou, ainda, porque não adquiriu as competências ou outros recursos necessários para realizá-la.

Pode ainda ocorrer a mudança, não rara, da gestão do programa, especialmente em períodos de mudança de governo, que pode não compreender exatamente o que a equipe de auditoria pretendia com aquelas recomendações, tendo em vista que não participou das discussões anteriores.

Dessa forma, demonstram-se, a seguir, os resultados obtidos da análise realizada.

Foi observado que existe um grupo de recomendações, consideradas frágeis, as quais foram denominadas de recomendações elásticas: que são aquelas em que o gestor, ao realizar qualquer movimento no sentido de implementá-la, esgota sua responsabilidade. O problema é que a equipe não pode fazer nada se não concordar com o que foi feito, tendo em vista que o gestor fez o que estava escrito, conforme o entendimento que a redação lhe permitiu.

Podem-se relacionar os seguintes exemplos, obtidos nos relatórios de auditoria operacional julgados pelo Tribunal de Contas do Estado de Pernambuco (TCE/PE, 2004b):

Promova ações de sensibilização junto aos diretores, quanto à importância de sua participação neste processo de monitoramento e controle, tendo em vista que as informações referentes ao desempenho dos professores e alunos de sua escola são de sua responsabilidade.

Observa-se que as possibilidades de ação do gestor são muitas, pois ele pode promover desde algumas reuniões com os diretores até um processo contínuo de discussões, com ampla divulgação dos benefícios inerentes à implementação do monitoramento e do controle de suas 
atividades. Assim, se o gestor fizer algumas reuniões, a recomendação estará atendida e a equipe de auditoria não poderá questionar o não atendimento. O problema é saber se a ação foi suficiente para resolver o problema anteriormente identificado pela auditoria.

Foi identificado outro grupo de recomendações com fragilidades, as quais foram denominadas de recomendações com foco em objetos voláteis, que são aquelas que estão direcionadas a objetos que poderão com certa facilidade não mais existir ou perder importância à época dos monitoramentos. São observadas com frequência recomendações focadas em Sistemas Informatizados específicos que, por uma série de motivos, podem não estar mais sendo utilizados pelo programa à época do monitoramento. O exemplo dado a seguir esclarece a questão:

Implementar rotina para que várias denúncias comuns à mesma infração possam ser cadastradas na base de dados do SCP com o mesmo 'Nome da Solicitação' e 'Título', havendo também um elo entre estas. (TCE/PE, 2003a).

O SCP é um sistema informatizado específico, utilizado pela Companhia Pernambucana de Recursos Hídricos, o qual poderá ser substituído por outro e, dessa forma, a recomendação correrá o risco de não ser implementada. Se o gestor tiver o interesse em resolver o problema, ele levará em consideração a recomendação no próximo Sistema que o programa adotar; caso contrário, poderá alegar que não implementou porque houve a mudança.

Existem outros objetos voláteis que devem ser considerados, como, por exemplo, quando se solicita atuação com empresa prestadora de serviços que trabalha com a gestão do programa. Pode ocorrer que à época do monitoramento a empresa não mais exista ou por algum outro motivo não presta mais serviço ao programa, comprometendo a implementação da recomendação. Ou ainda:

Continue avaliando anualmente todos os alunos da $2^{\underline{a}}$ etapa das escolas estaduais, com os critérios do SAEPE, mas que também se contemple, pelo menos uma amostra de alunos das escolas municipais, que funcione como um grupo de controle. (TCE/PE, 2004b).

Observa-se que os critérios do SAEPE podem, em futuro próximo, não serem considerados os mais adequados e, portanto, essa possibilidade deve ser motivo de cuidados por parte das equipes de auditoria.

Existem também aquelas que foram denominadas de recomendações com foco em planejamento, que são aquelas que propõem ações de planejamento, mas não expressam que deve ser colocado em prática, ou seja, as ações previstas nesse planejamento devem ser implementadas, senão o problema anteriormente identificado permanecerá sem solução.

Elaborar Plano de Ação Integrada para fazer face às dificuldades externas enfrentadas pelos alunos de EJA com vistas a estimular sua permanência e bom aproveitamento, ou implementar as ações previstas na 'Brigada Paulo Freire' que visam a continuidade dos estudos de jovens e adultos. (TCE/PE, 2007).

Como se pode observar, caso a gestão opte pela elaboração de Plano de Ação Integrada, a recomendação não estará prevendo que esse plano seja implementado e, portanto, mesmo que ele não saia do papel, a gestão terá atendido a recomendação. 
Observou-se também que algumas recomendações se caracterizam por definir normas formais ou informais à gestão e foram denominadas de recomendações normativas. O risco dessas recomendações é a possibilidade de as normas estabelecidas tornarem-se "letra morta", ou seja, não serem cumpridas e, então, mesmo que a recomendação seja atendida, o problema não seria solucionado.

A recomendação a seguir é um bom exemplo desse caso: "Elabore norma que estabeleça sanções para os diretores de escolas que sejam inadimplentes no dever de prestar contas da merenda escolar recebida". (TCE/PE, 2004a).

Logo se percebe que esse caso exige firmeza por parte da gestão do programa e que, se apesar de estabelecida a norma, a punição aos diretores inadimplentes não ocorrer, ocorrerá o descrédito com relação à norma que, provavelmente, não será levada a sério no futuro.

Há também outro grupo que foi denominado de recomendações agrupadas, que são aquelas em que duas ou mais recomendações são descritas em bloco, como, por exemplo:

A CEAGEPE deve elaborar um cronograma de fiscalizações, informando a SPRRA sobre os resultados de cada fiscalização, para que a Secretaria supervisione e tome as medidas necessárias para solucionar as deficiências encontradas. (TCE/PE, 2003b).

A gestão poderá, nesse caso, elaborar o cronograma e informar à Secretaria, mas essa poderá, por algum motivo, não supervisionar e, consequentemente, não tomar as respectivas medidas saneadoras. Como cada recomendação recebe uma classificação no monitoramento, surge a seguinte dificuldade: a recomendação seria classificada como em implementação (fase inicial ou avançada), que passaria uma ideia de que há tendência de melhora no programa, mas que poderia mascarar a falta de vontade de implementar a parte mais importante e complexa da recomendação.

Resta, então, verificar se a equipe de auditoria, diante de situações semelhantes às que foram citadas, poderá adotar uma postura preventiva e adotar um plano de contingências, caso os riscos elencados venham a se concretizar.

\section{Proposição de plano de contingência}

No presente caso, não foi necessária a utilização de ferramentas robustas, citadas abaixo, utilizadas por especialistas em inteligência competitiva, pois a simples análise das recomendações foram suficientes para obter resultados que apontam para a possibilidade e oportunidade da elaboração de um plano de contingência.

As tecnologias de informação (TI) são muito úteis para apoiar o processo de inteligência competitiva, dentre elas pode-se citar: groupware, gestão eletrônica de documentos (GED), Internet, Intranet, Extranet e sistemas de informação... as principais TI aplicadas à geração de informações oportunas dos sistemas de informação são: Executive Information System (EIS); Enterprise Resource Planning (ERP); Sistema de Apoio a Decisões (SAD); Sistemas Gerenciadores de Bancos de Dados (SGBD); Data Warehouse (DW); Inteligência Artificial (IA); Sistemas Especialistas (SE); Data Mining

(DM); Database Marketing (DBM); recursos de Internet; automação de escritórios; On-Line Analytic Processing (OLAP); On-Line Transaction Processing (OLTP) entre outras. (VALENTIM, 2003).

Rev. Adm. UFSM, Santa Maria, v. 3, n. 2, p. 191-204, mai./ago. 2010 
Diante do exposto, observou-se que, com a ocorrência de recomendações que apresentam as fragilidades identificadas nesta pesquisa, poder-se-ia adotar as seguintes medidas ou procedimentos de segurança:

a) com relação às recomendações elásticas, é preciso considerar que deveriam ser evitadas em trabalhos futuros, mas, uma vez emitidas e julgadas, poder-se-iam fazer contatos periódicos com a gestão do programa, antes da realização do primeiro monitoramento, para verificar se não está havendo interpretação equivocada quanto ao real sentido da recomendação. Por outro lado, se ocorrer de, à época do monitoramento, observar-se que a implementação da recomendação minimiza ou distorce o seu sentido, a equipe deverá emitir nova recomendação, mais clara, e cobrá-la com mais ênfase no próximo monitoramento. A equipe poderá antecipadamente já possuir uma nova redação para a recomendação, adotando uma postura preventiva;

b) quanto às recomendações com foco em objetos voláteis, poder-se-ia adotar esquema em que o gestor precisasse avisar à equipe de auditoria qualquer alteração com relação aos objetos foco dessas recomendações, para que, à época do monitoramento, não houvesse surpresas. Porém, se a mudança só foi identificada durante o monitoramento, é necessário estudar o novo objeto, para fazer nova recomendação, com o cuidado de torná-la mais genérica. Por exemplo, se o antigo sistema informatizado não gerava um relatório importante, não se deveria recomendar que o novo sistema o fornecesse, mas sim que a gestão criasse condições para dispor daquele relatório;

c) quanto às recomendações com foco em planejamento, poder-se-iam fazer alguns contatos antes do monitoramento, para verificar se o planejamento está sendo implementado, mas, se durante o monitoramento, perceber-se que o planejado não está caminhando para a implementação, poder-se-ia fazer nova recomendação, em que ficasse claro que o planejamento realizado deve ser implementado e, assim, não seja possível tergiversar quanto ao assunto. O que se observa é que esse cuidado pode ser tomado no momento em que se faz a primeira recomendação e deve servir de alerta para trabalhos futuros;

d) quanto às recomendações normativas, deve-se verificar à época do monitoramento não apenas se as normas foram estabelecidas, mas também se estão sendo cumpridas. Caso não estejam, poder-se-ia fazer nova recomendação em que ficasse claro que a gestão deveria garantir o cumprimento da norma;

e) quanto às recomendações agrupadas, se a equipe de auditoria perceber no monitoramento que a gestão está concentrada apenas em resolver a parte mais simples e menos importante da recomendação, poderia desmembrar a recomendação em outras duas ou três, conforme o caso, para que a parte mais importante e não atendida possa ser considerada uma recomendação não implementada.

Diante dessas observações, percebe-se que é possível preparar um Plano Contingencial para o caso dos riscos percebidos se concretizarem, a partir de análise e tratamento de cada recomendação, a fim de se estar preparado para garantir que a recomendação seja eficaz.

\section{Conclusão}

Pode-se concluir que, a partir da premissa conceitual da inteligência competitiva e da análise dos relatórios de auditoria - sem a necessidade do auxílio de ferramenta poderosa utilizada por profissionais que trabalham nessa área de atuação - observaram-se diversas fragilidades que podem comprometer a eficácia da implementação das recomendações emitidas 
pela auditoria operacional, as quais, uma vez identificadas, permitirão ao gestor do órgão de fiscalização governamental estabelecer uma estratégia preventiva bem como uma estratégia contingencial para fazer face aos fatores de risco, caso eles se concretizem.

\section{Referências}

BRASIL. Constituição, de 05 de outubro de 1988. Constituição da República Federativa do Brasil. 28. ed. São Paulo: Atlas, 2007.

BRASIL. Tribunal de Contas da União. Técnicas de auditoria: indicadores de desempenho e mapa de produtos. Brasília: TCU, Coordenadoria de Fiscalização e Controle, 2000. Disponível em: <http:// www.contraloriagen.gov.co/html/comtema/pdf/ tdesempeno.pdf >. Acesso em: 10 set. 2007.

CARVALHO, José Francisco de. A modernização dos tribunais de contas: um imperativo da democracia. Gestão Pública e Controle Externo, Salvador, v.1, n.1, p. 115-140, nov. 2005.

INTOSAI. International Organization of Supreme Audit Institutions. Diretrizes para aplicação de normas de auditoria operacional. Tradução de Inaldo da Paixão Santos Araújo e Cristina Maria Cunha Guerreiro. Salvador: Tribunal de Contas do Estado da Bahia, 2005.

PALOP, F.; VICENTE GOMILA, J. M. Vigilância tecnológica e inteligência competitiva. Valencia: COTEC, 1999. Disponível em:< http:// www.infocalidad.net/aa/doc/100300c.pdf > . Acesso em: 28 ago. 2007.

POZZEBON, M.; FREITAS, H. M. R. de; PETRINI, M. Pela integração da inteligência competitiva nos Enterprise Information Systems (EIS). Ci. Inf., Brasília, v. 26, n. 3, 1997 . Disponível em: <http:// w w w . S c i e l o scielo.php?script $=$ sci_arttext $\&$ pid $=$ S0100$19651997000300003 \& \operatorname{lng}=\mathrm{en} \& \mathrm{nrm}=\mathrm{iso}$. Acesso em: 29 ago. 2007.
RIBEIRO, A. S. M. Corrupção e controle na administração pública brasileira. São Paulo: Atlas, 2004.

SANTA CATARINA. Plano de preparação para o enfrentamento da pandemia de influenza. 2006. Disponível em: < http://www.dive.sc.gov.br/conteudos/ noticias/PLANODEINFLUENZA.pdf > . Acesso em: 12 set. 2007.

SANTOS AMARO, M.O. Sua organização está preparada para uma contingência?. Palestra no II Simpósio de Tecnologia da Informação da Marinha INFORMAR 2005. Marinha do Brasil; Escola de Guerra Naval: Rio de Janeiro, nov. 2005.

SOUZA FILHO, A.M. Planos nacionais de contingência para atendimento a derramamento de óleo: análise de países representativos das américas para implantação no caso do Brasil. 2006. 217 f. Dissertação (Mestrado em Planejamento Energético)-Universidade Federal do Rio de Janeiro, Rio de Janeiro, 2006. Disponível em: <http://www.ppe.ufrj.br/ppe/ production/tesis/amfilho.pdf > . Acesso em: 20 ago. 2007.

TCE. Tribunal de Contas do Estado de Pernambuco. Auditoria de Desempenho da Companhia Pernambucana de Meio Ambiente. 2003a. Disponível em: <http://www.tce.pe.gov.br/anop/files_audi/ cprh/ANOpCPRH.pdf>. Acesso em: 10 set. 2007.

Avaliação do Programa do Leite de Pernambuco. 2003b. Disponível em: <http:// www.tce.pe.gov.br/anop/files_audi/prog_leite/ ANOpPrograma.pdf>. Acesso em: 10 set. 2007.

. Avaliação do Programa da Merenda Escolar do Estado de Pernambuco. 2004a. Disponível em: <http://www.tce.pe.gov.br/anop/files_audi/penae/ prog_merenda_escolar_pe_anop.pdf $>$. Acesso em: 10 set. 2007. 
. Avaliação do Programa Estadual de Alfabeti-

zação. 2004b. Disponível em: <http:// www.tce.pe.gov.br/anop/files_audi/alfabetizacao/ ProgramaEstadualdeAlfabetização.pdf $>$. Acesso em: 10 set. 2007.

. Avaliação do Programa de Saúde Ambiental da Cidade do Recife. 2005. Disponível em: <http:// www.tce.pe.gov.br/anop/files_audi/ ANOP_PSA.pdf>. Acesso em: 10 set. 2007. . Avaliação do Programa Educação Básica de Jovens e Adultos. Resumo de auditoria no prelo. Recife: Tribunal de Contas do Estado de Pernambuco, 2007.

VALENTIM, M.L.P. et al. O processo de inteligência competitiva em organizações. DataGramaZero - Revista de Ciência da Informação, v.4 n.3 jun. 2003.

. Inteligência competitiva em organizações:

dado, informação e conhecimento.

DataGramaZero, Rio de Janeiro, v.3, n.4, ago. 2002. Disponível em: <http://www.dgz.org.br/ ago02/Art_02.htm > . Acesso em: 30 ago. 2002. 